\title{
Hemodynamic Changes during Endotracheal Suctioning Are Mediated by Increased Autonomic Activity
}

\author{
JEFFREY L. SEGAR, DAVID C. MERRILL, MARK W. CHAPLEAU, AND JEAN E. ROBILLARD \\ Departments of Pediatrics [J.L.S., J.E.R.], Obstetrics and Gynecology [D.C.M.], Internal Medicine [M.W.C.], and \\ the Cardiovascular Center, University of Iowa, Iowa City, Iowa 52242
}

\begin{abstract}
Endotracheal suctioning of intubated infants produces profound changes in cardiovascular and cerebral hemodynamics, but the mechanisms regulating these changes are not fully understood. To determine the role of the autonomic nervous system in regulating these physiologic changes, we investigated the effects of endotracheal suctioning on heart rate (HR), mean arterial blood pressure (MABP), and renal sympathetic nerve activity (RSNA) in nine ventilated newborn lambs. In the first part of the study $(n=6)$, ventilation was interrupted for suctioning. With suctioning (15 s), HR decreased by $39 \pm 6 \%(p<0.05)$, whereas MABP and RSNA increased significantly $(p<$ $0.05)$ by $36 \pm 5 \%$ and $68 \pm 8 \%$, respectively. These changes were significantly $(p<0.05)$ larger than changes observed during disconnection from the ventilator $(15 \mathrm{~s})$ without suctioning. Administration of atropine $(0.02 \mathrm{mg} /$ $\mathrm{kg}$ ) blocked the $\mathrm{HR}$ response to suctioning without altering MABP or RSNA changes. After bilateral vagotomy, suctioning produced no changes in any parameter. When a closed tracheal suction system was used and ventilation was maintained, suctioning again resulted in significant $(p$ $<0.05)$ increases in MABP $(+10 \pm 3 \%)$ and RSNA $(+34$ $\pm 5 \%)$ and a decrease in HR $(-15 \pm 4 \%)$. These data suggest that suctioning stimulates sympathoexcitatory receptors localized in large airways whose afferent fibers course within the vagus, resulting in increased sympathetic activity, which induces peripheral vasoconstriction and elevates MABP. In contrast, the $H R$ response appears to be mediated by increased parasympathetic activity as this is abolished by atropine. (Pediatr Res 33: 649-652, 1993)
\end{abstract}

\section{Abbreviations}

HR, heart rate

MABP, mean arterial blood pressure

RSNA, renal sympathetic nerve activity

DX, disconnection from ventilator

SUX, endotracheal suctioning

SUX-A, endotracheal suctioning after atropine administration

SUX-VX, endotracheal suctioning after bilateral vagotomy

Endotracheal suctioning of intubated infants is routinely per-

Received July 28, 1992; accepted January 22, 1993.

Correspondence: Jeffrey L. Segar, M.D., Assistant Professor, Department of Pediatrics, University of Iowa, Iowa City, IA 52242.

Supported in part by National Institutes of Health Grants DK-44756, DK43961, and HL-14388. J.L.S. was supported by a National Research Service Award, HL-08170.

'Presented in part to the The Society of Pediatric Research, Baltimore, MD, May 1992. formed to remove secretions and prevent obstruction of the endotracheal tube. In many intensive care nurseries, this procedure is performed at standard intervals regardless of gestational age and often requires disconnection from the ventilator. However, suctioning has been shown to increase arterial blood pressure, cerebral blood flow velocity, and intracranial pressure and to induce bradycardia and hypoxemia (1-6). Such alterations in systemic and cerebral hemodynamics may place the preterm infant at increased risk for intraventricular hemorrhage $(2,7)$. Although a number of phenomena have been postulated to explain these complex cardiovascular manifestations, the mechanisms explaining these changes are not fully understood $(1,2$, $5,8,9)$. We therefore investigated the role of the autonomic nervous system in regulating the blood pressure and HR responses to endotracheal suctioning in ventilated newborn lambs.

\section{MATERIALS AND METHODS}

Studies were conducted in chronically instrumented newborn lambs $(n=9)$ between 3 and $7 \mathrm{~d}$ of age. Anesthesia and surgery were performed as previously described. ${ }^{10}$ Briefly, with the lambs under anesthesia in sterile conditions, polyethylene catheters were placed into the femoral arteries and veins bilaterally. The left renal pedicle was exposed through a flank incision. After isolation of a branch of the left renal nerve bundle, platinum electrodes were secured onto the nerve for recording RSNA as previously described (10). A plastic-coated copper wire used as a ground wire was secured in the paravertebral muscle and the flank incision was closed. A midline incision was made over the trachea, and the vagal nerves on both sides were freed from the sympathetic trunk and surrounding structures. Loops of umbilical tape were placed around the nerves and exteriorized to allow access to the nerves for vagotomy at a later time. Catheters were tunneled subcutaneously and secured to the lamb's back using elastic bandages. Ampicillin sodium $(1 \mathrm{~g})$ was administered before surgery and at 48-h intervals. At least $24 \mathrm{~h}$ were allowed for recovery from surgery before experiments were performed.

During the study, lambs were kept immobilized in a slingframe assembly placed inside a Faraday cage. The animals were sedated with diazepam $(0.2 \mathrm{mg} / \mathrm{kg}$ i.v. $)$, curarized with vecuronium bromide $(0.1 \mathrm{mg} / \mathrm{kg}$ i.v.), intubated, and ventilated to maintain arterial $\mathrm{pH}$ and $\mathrm{PCO}_{2}$ at values similar to those during spontaneous respiration. Arterial $\mathrm{PO}_{2}$ values were maintained between 13.3 and $17.3 \mathrm{kPa}$ (100 and $130 \mathrm{~mm} \mathrm{Hg}$ ). The administration of vecuronium, a nondepolarizing muscle relaxant, was necessary to eliminate muscle movements that interfere with nerve recording.

During each experiment, MABP and HR were continually monitored. The renal nerve electrodes and ground wire were attached to a high-impedence probe (HIP5, Grass Instruments, Quincy, MA). The neural signal was amplified $(\times 20000)$ and filtered with a low-frequency cutoff at $100 \mathrm{~Hz}$ and a high- 
frequency cutoff at $1 \mathrm{kHz}$ using a Grass Bandpass Amplifier (P511). The amplified and filtered signal was visually displayed on an oscilloscope (511A, Tektronix, Beaverton, OR), routed to a Grass AM8 audio monitor. The amplified neural signal was rectified to make all voltages positive and integrated at rates of $0.5-1.0 \mathrm{~Hz}$ using a 9873B Beckman voltage integrator (Beckman Instruments, Fullerton, CA). The rate of integration depended upon the quality of the neural signal and remained constant during all parts of the experiment for each animal. The integrated voltage and neurogram signals, as well as all hemodynamic data, were displayed on a Beckman R611 Dynograph recorder and simultaneously recorded on-line to an IBM-XT computer using Labtech Notebook (Laboratory Technologies, Wilmington, MA).

Two different methods of endotracheal suctioning (group 1, suctioning during interrupted ventilation; group 2, suctioning during continuous ventilation) were used to determine which neural pathways mediate the cardiovascular response to endotracheal suctioning and to separate the primary reflex response from secondary changes due to the cessation of lung expansion. In the first group, recordings were made 1 ) while the lamb was disconnected from the ventilator (DX);2) during endotracheal suctioning, for which the ventilator was disconnected (SUX); 3) during suctioning preceded by administration of atropine $(0.02 \mathrm{mg} / \mathrm{kg}$ i.v.; SUX-A); and 4) during suctioning preceded by bilateral vagotomy (SUX-VX). In one animal, vagotomy was not performed. Lambs were disconnected from the ventilator for $15 \mathrm{~s}$ for each procedure. Suctioning was performed by passing a $5 \mathrm{Fr}$ suction catheter via the endotracheal tube until slight resistance, thought to be from contact with the wall of the airway, was met. Suction was then applied as the catheter was slowly withdrawn, advanced, then withdrawn again. Experiments were performed in random order with the exception that vagotomy was performed last. A 5- to 10-min recovery period was allowed between each suction episode. After the series of studies involving atropine, $30 \mathrm{~min}$ were allowed before proceeding with the next series of experiments. After vagotomy, a 1 -h equilibration period was allowed for HR and MABP to return to baseline values before preceding with the experiment. At the end of the experiment, complete inhibition of nerve activity was assessed using an i.v. infusion of the ganglionic blocking agent tetraethylammonium bromide $(10 \mathrm{mg} / \mathrm{kg})$. Noise within the neural signal was then measured and subtracted from the recorded signal before any calculation of change in RSNA.

In the second group of animals $(n=3)$, a closed tracheal suction system (Trach Care Neonatal, Ballard Medical Products, Draper, UT), in which ventilation is not discontinued during suctioning, was used. The suction catheter was modified such that it could be extended beyond the end of the endotracheal tube. Recordings were made $l$ ) during suction with the catheter positioned at but not beyond the end of the endotracheal tube, 2) during suction with the catheter advanced until resistance was met, and 3) with the catheter advanced until resistance was met but without negative pressure suction. The time course of these studies was similar to those outlined above.

Baseline values for HR, MABP, and RSNA were obtained by averaging the values of these parameters over the $30 \mathrm{~s}$ preceding each intervention. Maximum instantaneous changes in $\mathrm{HR}$, MABP, and RSNA with each procedure were recorded and expressed as percent change from baseline values. Each procedure was repeated two to four times, and average values for changes in each measured parameter were calculated for individual animals. These average values were then used for data analysis performed by one-way analysis of variance with repeated measures. If the $F$ statistic was found to be significant, comparison among means was performed by the Scheffe procedure (11). The results for each procedure are expressed as mean \pm SEM. Differences were considered significant when $p$ was less than 0.05 .

All procedures were performed within the regulation of the Animal Welfare Act and the NIH Guide for the Care and Use of Laboratory Animals.

\section{RESULTS}

Figure 1 shows tracings recorded from a newborn lamb illustrating the effects of ventilator disconnection and endotracheal suctioning on HR, MABP, and RSNA. Disconnection of the ventilator alone for $15 \mathrm{~s}$ was associated with a dramatic decrease in HR, an increase in MABP, and an initial increase in RSNA followed by inhibition of activity. Similar changes in these parameters, but of significantly greater magnitude, were seen with suctioning.

To investigate the mechanisms and neural pathways mediating the cardiovascular changes associated with endotracheal suctioning, studies were repeated after administration of atropine and after bilateral vagotomy (Fig. 2). The administration of atropine had no measurable effect on changes in MABP or RSNA in response to suctioning. However, the $H R$ response was greatly attenuated. In contrast, bilateral vagotomy completely inhibited the cardiovascular and RSNA changes associated with suctioning.

Within group 1, a significant increase in MABP from baseline $(87 \pm 3 \mathrm{~mm} \mathrm{Hg})$ was seen during DX, SUX, and SUX-A $(p<$ 0.05 ; Fig. 3). This increase was significantly larger $(p<0.05)$ with SUX $(32 \pm 3 \mathrm{~mm} \mathrm{Hg})$ and SUX-A $(36 \pm 5)$ than with DX $(17 \pm 4)$ alone. In contrast, no significant change in MABP was seen during SUX-VX.

RSNA increased significantly $(p<0.05)$ after DX $(11 \pm 8 \%)$, SUX $(68 \pm 8 \%)$, and SUX-A $(66 \pm 9 \%$, Fig. 4). The increases
A
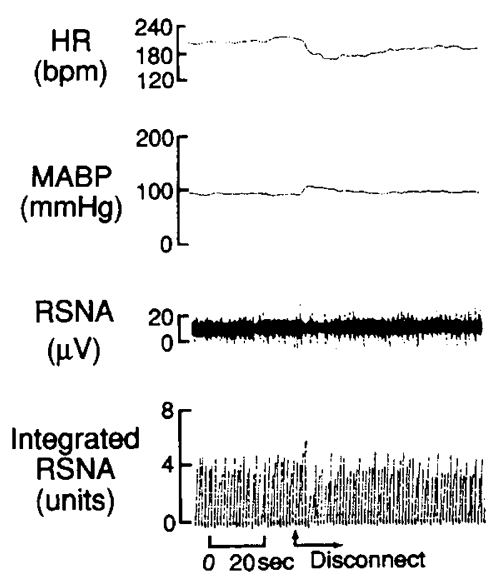

\section{B}
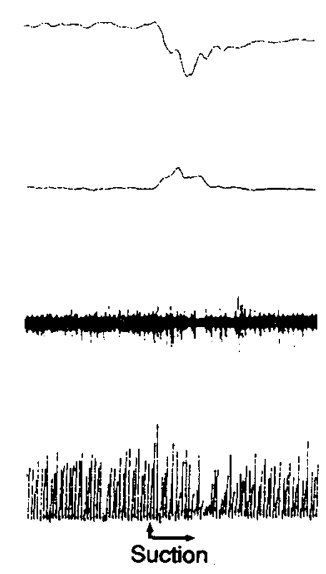

Fig. 1. Representative recording from a newborn lamb illustrating changes in HR, MABP, RSNA, and integrated RSNA in response to $(A)$ disconnection from the ventilator and $(B)$ endotracheal suctioning.

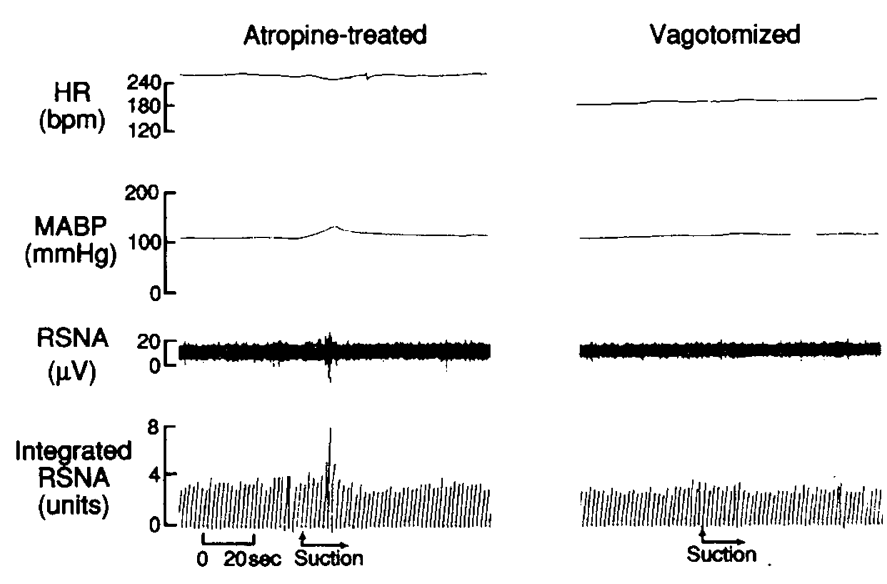

Fig. 2. Representative recording from a newborn lamb illustrating changes in HR, MABP, RSNA, and integrated RSNA associated with endotracheal suctioning after administration of atropine and bilateral vagotomy. 


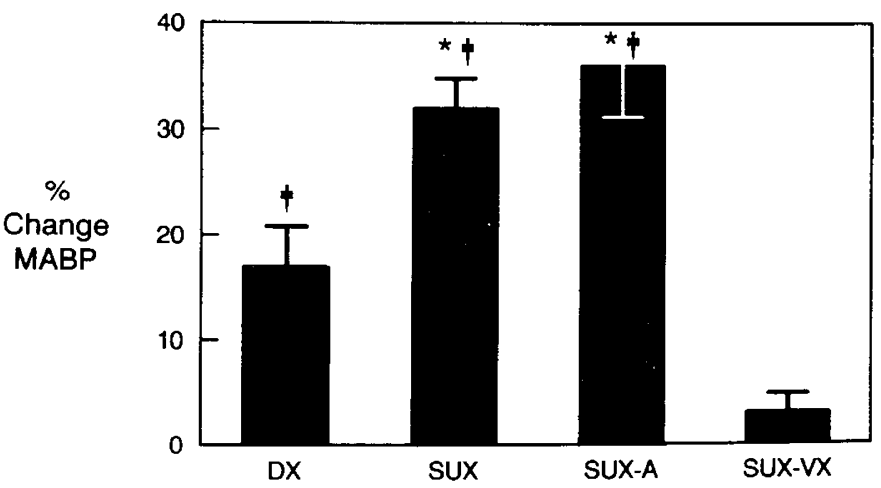

Fig. 3. Changes in MABP during endotracheal suctioning. Values are means \pm SEM. ${ }^{*}, p<0.05$ compared with DX; $\ddagger, p<0.05$ compared with baseline $(0 \%)$ and SUX-VX.

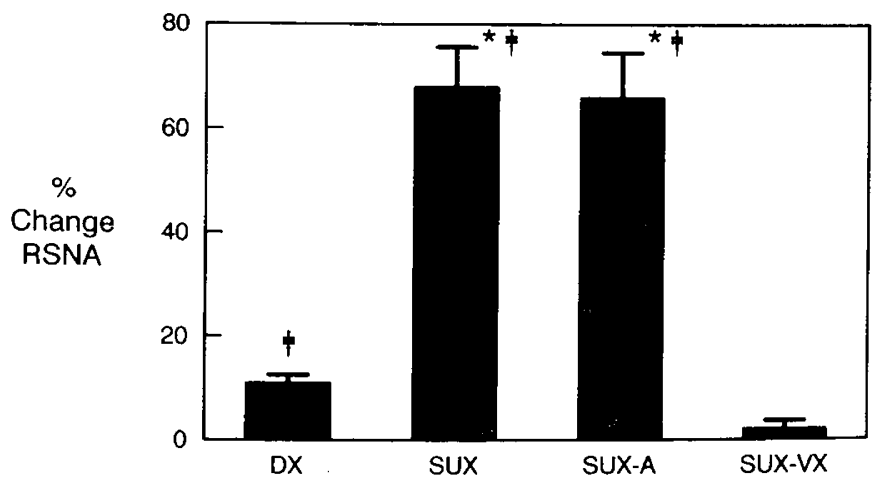

Fig. 4. Changes in RSNA during endotracheal suctioning. Values are means \pm SEM. ${ }^{*}, p<0.05$ compared with DX;,$+ p<0.05$ compared with baseline $(0 \%)$ and SUX-VX.

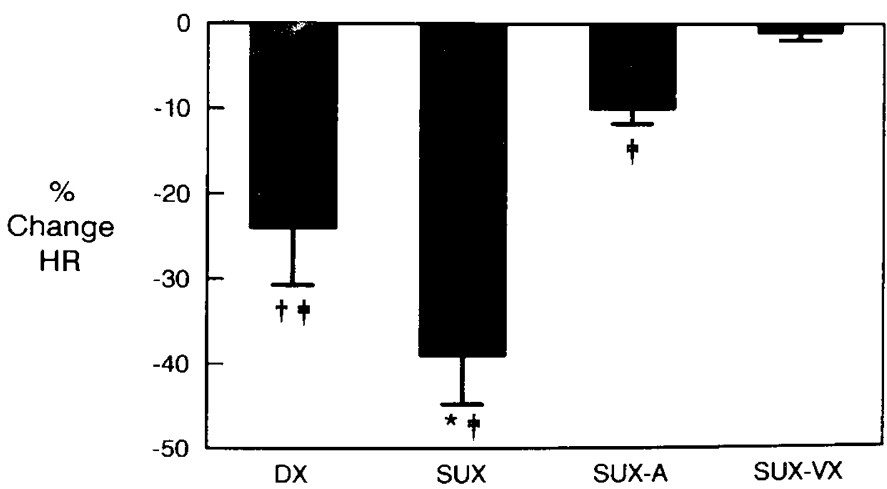

Fig. 5. Changes in HR during endotracheal suctioning. Values are means \pm SEM. ${ }^{*}, p<0.05$ compared with other groups; $\dagger, p<0.05$ compared with SUX-A; $\ddagger, p<0.05$ compared with baseline $(0 \%)$ and SUX-VX.

were significantly larger $(p<0.05)$ in SUX and SUX-A than after DX. Vagotomy abolished the renal nerve response to endotracheal suctioning (SUX-VX).

The decrease in HR from baseline $(220 \pm 7 \mathrm{bpm})$ was significantly greater after SUX $(-39 \pm 6 \%, p<0.05)$ than after DX $(-24 \pm 7 \%)$ or after atropine administration $(-10 \pm 2 \%)$ and vagotomy $(-1 \pm 1 \%$, Fig. 5). Atropine greatly attenuated the bradycardic response to suctioning, although a significant decrease $(p<0.05)$ from baseline still occurred, whereas HR after SUX-VX did not significantly differ from baseline levels.

Within group 2, in which a closed tracheal suction system was used, negative pressure suction applied through catheters advanced not beyond the tip of the endotracheal tube produced no significant changes in MABP, RSNA, or HR (Fig. 6). In contrast, with advancement of the catheter until slight resistance was met,

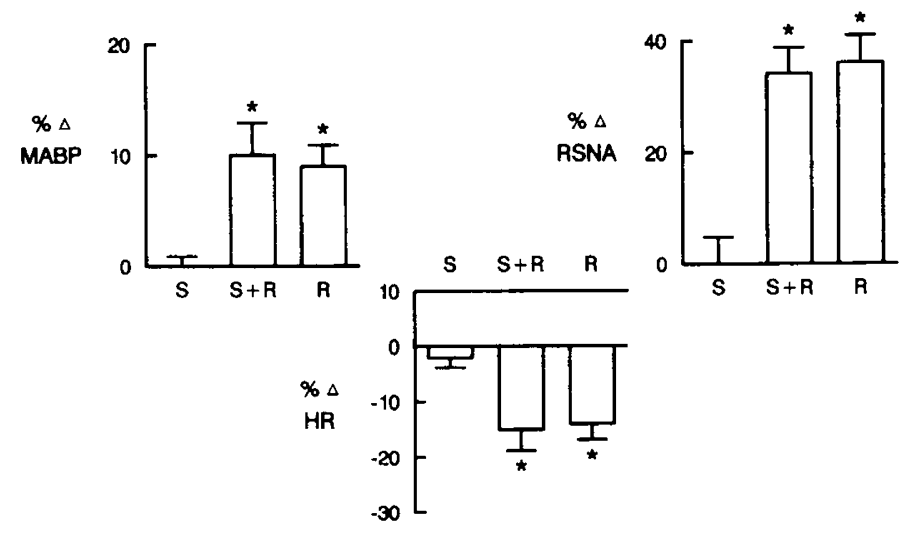

Fig. 6. Changes in physiologic parameters with endotracheal suctioning during continuous ventilation. $\mathrm{S}$, negative pressure suction with catheter at tip of endotracheal tube; $\mathrm{R}$, catheter advanced until slight resistance met. Values are means \pm SEM. ${ }^{*}, p<0.05$ compared with $\mathrm{S}$ and baseline (0\%).

significant $(p<0.05)$ increases in MABP and RSNA and a decreases in HR were seen regardless of whether negative pressure suction was applied.

\section{DISCUSSION}

These studies indicate that pronounced physiologic changes occur in response to several methods of endotracheal suctioning in ventilated newborn lambs. Our observations confirm the findings of others that suctioning is associated with a decrease in HR and an increase in blood pressure $(1-4,6,9)$. Furthermore, the results suggest that these hemodynamic changes are modulated by activation of the autonomic nervous system.

Little information is available on the morphologic properties and physiologic actions of airway irritant receptors in the newborn $(12-14)$. Previous studies $(12,14)$ have focused mainly on laryngeal receptors because the upper airways (nose to larynx) are more densely innervated than the lower airways of the lung. Application of water and other irritants to the larynx of newborn lambs produces bradycardia, hypertension, and blood flow redistribution $(15,16)$. These responses appear to be neurally mediated as the vasoconstriction and bradycardia are abolished by $\alpha$-adrenergic blockade and atropine, respectively (16).

Several findings in the present study, including that 1) MABP and RSNA increased and HR decreased more during SUX than during $\mathrm{DX}, 2)$ negative pressure suction alone produced no significant physiologic changes, and 3 ) with uninterrupted ventilation, advancement of the catheter until resistance was met resulted in significant alterations in MABP, RSNA, and HR regardless of whether negative pressure suction was applied, demonstrate that mechanical deformation of the walls of the large airways directly influences cardiovascular function. These results further suggest that in these studies, this mechanical deformation stimulates rapidly adapting or irritant receptors within the lower airway, resulting in increased sympathetic activity, peripheral vasoconstriction, and elevation in blood pressure. Because no significant physiologic response to suctioning was demonstrated after vagotomy, it appears that afferent fibers from these receptors course within the vagus nerve, as do other types of receptors within the pulmonary tree (17). Primary afferent fibers originating from a variety of visceral sensory endings, including rapidly adapting pulmonary receptors, terminate within the nucleus of the tractus solitarius $(18,19)$, a structure vital in the autonomic regulation of cardiovascular function. Thus, input from these fibers may contribute to modulation of $\mathrm{HR}$ and blood pressure via regulation of the sympathetic and parasympathetic nervous systems.

The bradycardia observed with suctioning was almost completely abolished by atropine, indicating that the HR response is 
primarily mediated by parasympathetic stimulation. The mechanisms regulating this increase in parasympathetic activity could not be determined from this study. Activation of irritant receptors by chemical agents evokes bradycardia, the response being mediated by vagal pathways (20). In addition, increased arterial blood pressure stimulates carotid and aortic baroreceptors, which may further contribute to the bradycardic response via activation of parasympathetic pathways (21). Administration of atropine had no significant effect on MABP or RSNA changes, suggesting that parasympathetic stimulation after suctioning participated little in the regulation of MABP and RSNA.

Although the magnitude of the physiologic changes observed were larger during SUX than during DX alone, significant changes in HR, MABP, and RSNA occurred with DX. These changes could have been initiated by a small decrease in arterial $\mathrm{PO}_{2}$ or, more likely, unloading of pulmonary stretch receptors during DX. Studies examining the role of pulmonary stretch receptors in modulating cardiovascular responses have shown that stimulation of these receptors inhibits vagal efferent discharge and decreases efferent sympathetic activity, thus inducing cardiac acceleration and peripheral vasodilation $(22-25)$. In the absence of lung inflation, however, there is an increase in parasympathetic activity with associated inhibition of HR (25). Interestingly, Grogaard et al. (16) found that reflex bradycardia and hypertension during application of water to the larynx of newborn lambs were attenuated when reflex apnea and cessation of ventilatory movements were prevented by artificial ventilation, independent of changes in arterial blood gas values. Although the magnitude of the physiologic changes in response to suctioning in the present study is not as great during continuous ventilation as during interrupted ventilation, there is a large influence of suctioning on cardiovascular hemodynamics and the autonomic system that appears unrelated to additional loss of lung volume.

The cardiovascular changes noted during tracheal suction are characteristic of the physiologic response to hypoxemia (26). It is unlikely, however, that hypoxemia contributed significantly to the observed physiologic responses, as has been suggested by others $(1,5)$. First, the lambs were initially made slightly hyperoxic to avoid the development of hypoxemia. Studies in infants have shown that, with $15 \mathrm{~s}$ of apnea, transcutaneous $\mathrm{PO}_{2}$ values fall by only $13 \%$ (27). Second, in ventilated newborn lambs with induced hypoxia [arterial $\mathrm{PO}_{2}=36 \pm 1 \mathrm{~mm} \mathrm{Hg}(4.8 \pm 0.1$ $\mathrm{kPa})$ ], Grogaard et al. (16) found that $\mathrm{HR}$ remained unchanged and MABP increased by only $7 \%$. Third, the cardiovascular changes began within $2 \mathrm{~s}$ of disconnection of the ventilator or suctioning. It is unlikely that significant changes in arterial blood gas measurements could occur over such a short time period. Nonetheless, development of hypoxemia during endotracheal suctioning remains a potentially serious complication in the newborn. Had we not maintained an elevated arterial $\mathrm{PO}_{2}$ and effectively preoxygenated the animals before suctioning, as advocated by several investigators $(1,5)$, the physiologic responses may have been more profound.

In summary, this study demonstrates that there are profound neurally mediated cardiovascular reflex responses to several methods of endotracheal suctioning. In the presence of a pressure-passive cerebral circulation, as occurs in the preterm infant $(7,28)$, such neurally mediated increases in systemic blood pressure may produce significant changes in cerebral blood flow and place the neonate at risk for the development of intraventricular hemorrhage $(7,8)$. Understanding the physiologic alterations induced by this commonly performed procedure may aid us in providing care to the high-risk infant.

Acknowledgments. The authors thank Bruce Smith and Oliva McWeeny for their technical assistance.

\section{REFERENCES}

1. Simbrunner G, Coradello H, Fodor M, Havelec L, Lubec G, Pollak A 1981 Effect of tracheal suction on oxygenation, circulation, and lung mechanics in newborn infants. Arch Dis Child 56:326-330

2. Perlman JM, Volpe JJ 1983 Suctioning in the preterm infant: effects on cerebral blood flow velocity, intracranial pressure, and arterial blood pressure. Pediatrics 72:329-334

3. Ninan A, O'Donnell M, Hamilton K, Tan L, Sankaran K 1986 Physiologic changes induced by endotracheal instillation and suctioning in critically ill preterm infants with and without sedation. Am J Perinatol 3:94-97

4. Cordero L, Hon EH 1971 Neonatal bradycardia following nasopharyngeal stimulation. J Pediatr 78:441-447

5. Shah AR, Kurth CD, Gwiazdowski SG, Chance B, Delivoria-Papadopoulos M 1992 Fluctuations in cerebral oxygenation and blood volume during endotracheal suctioning in premature infants. J Pediatr 120:769-774

6. Fanconi S, Duc G 1987 Intratracheal suctioning in sick preterm infants: prevention of intracranial hypertension and cerebral hypoperfusion by muscle paralysis. Pediatrics 79:538-543

7. Lou HC, Lassen NA, Friis-Hansen B 1979 Impaired autoregulation of cerebral blood flow in the distressed newborn infant. J Pediatr 94:118-121

8. Perlman JM, Goodman S, Kreusser KL, Volpe JJ 1985 Reduction in intraventricular hemorrhage by elimination of fluctuating cerebral blood-flow velocity in preterm infants with respiratory distress syndrome. $\mathrm{N}$ Engl J Med 312:1353-1357

9. Gunderson LP, McPhee AJ, Donovan EF 1986 Partially ventilated endotracheal suction. Am J Dis Child 140:462-465

10. Smith FG, Klinkefus JM, Kopp UC, Robillard JE 1990 Novel recordings of renal sympathetic nerve activity in conscious fetal and newborn lambs. Am J Physiol 258:F218-F221

11. Zar JH 1984 Biostatistical Analysis. Prentice Hall, Englewood Cliffs, NJ, pp 196-198

12. Fisher JT, Sant'Ambrosio G 1985 Airway and lung receptors and their reflex effects in the newborn. Pediatr Pulmonol 1:112-126

13. Fisher JT, Mathew OP, Sant'Ambrosio G 1991 Morphological and neurophysiological aspects of airway and pulmonary receptors. In: Haddad GG, Farber JP (eds) Developmental Neurobiology of Breathing. Marcel Dekker, New York, pp 219-244

14. Mortola JP, Fisher JT 1988 Upper airway reflexes in newborns. In: Mathew OP, Sant'Ambrogio G (eds) Respiratory Function of the Upper Airway. Marcel Dekker, New York, pp 303-357

15. Harding R, Johnson P, Johnston BE, McClellend ME, Wilkinson AR 1975 Cardiovascular changes in newborn lambs during apnea induced by stimulation of the laryngeal receptors with water. J Physiol (Lond) 256:35P

16. Grogaard J, Lindstrom DP, Stahlman MiT, Marchal F, Sundell H 1982 The cardiovascular response to laryngeal water administration in young lambs. J Dev Physiol 4:353-370

17. Sant'Ambrogio G 1987 Nervous receptors of the tracheobronchial tree. Annu Rev Physiol 49:611-627

18. Kalia M, Richter D 1985 Rapidly adapting pulmonary receptor afferents. I Arborization in the nucleus of the tractus solitarius. J Comp Neurol 233:308332

19. Jordan D, Spyer KM 1986 Brainstem integration of cardiovascular and pulmonary afferent activity. In: Cervero F, Morrison JFB (eds) Progress in Brain Research, Vol 67. Elsevier Science, New York, pp 295-314

20. Coleridge HM, Coleridge JCG 1986 Reflexes evoked from tracheobronchial tree and lungs. In: Fishman AP, Cherniack NS, Widdicombe JG (eds) Handbook of Physiology: The Respiratory System, Section 3. American Physiological Society, Bethesda, MD, pp 395-429

21. Mancia G, Mark AL 1983 Arterial baroreflexes in humans. In: Shepard JT, Abboud FM (eds) Handbook of Physiology: The Cardiovascular System, Section 1. American Physiological Society, Bethesda, MD, pp 755-793

22. Anrep GV, Pascual W, Rossler R 1936 Respiratory variations of the heart rate I. The reflex mechanism of the respiratory arrhythmia. Proc R Soc London [Biol] 119:191-217

23. Angell-James JE, Daly M De B 1978 The effects of artificial lung inflation on reflexly induced bradycardia associated with apnoea in the dog. J Physiol (Lond) 274:349-366

24. Bainton CR, Richter DW, Seller H, Ballantyne D, Klein JP 1985 Respiratory modulation of sympathetic activity. J Auton Nerv Syst 12:77-90

25. Abboud FM, Thames MD 1983 Interaction of cardiovascular reflexes in circulatory control. In: Shepard JT, Abboud FM (eds) Handbook of Physiology: The Cardiovascular System, Section 1. American Physiological Society, Bethesda, MD, pp 675-753

26. Cohn HE, Sacks EJ, Heymann MA, Rudolph AM 1974 Cardiovascular responses to hypoxemia and acidosis in fetal sheep. Am $\mathbf{J}$ Obstet Gynecol 120:817-824

27. Kahn A, Blum D, Waterschoot P, Engelman E, Smets P 1982 Effects of obstructive sleep apneas on transcutaneous oxygen pressure in control infants, siblings of sudden infant death syndrome victims, and near miss infants: comparison with the effects of central sleep apneas. Pediatrics 70:852-857

28. Milligan DWA 1980 Failure of autoregulation and intraventicular hemorrhage in preterm infants. Lancet 2:896-898 